\title{
Comparative analysis of choroidal thickness in third trimester pregnant women
}

\author{
Camila Zanella Benfica ${ }^{1,2^{*}} \mathbb{D}$, Teresinha Zanella ${ }^{3}$, Lucas Brandolt Farias ${ }^{1,2}$, Maria Lúcia Rocha Oppermann ${ }^{1,3}$, \\ Luis Henrique Santos Canani ${ }^{1,4}$ and Daniel Lavinsky ${ }^{1,2}$
}

\begin{abstract}
Background: The impact of pregnancy on the choroid is still under investigation. The aim of this study is to compare choroidal thickness measurements of healthy pregnant women in the third trimester and healthy non-pregnant women using spectral-domain optical coherence tomography (OCT).

Methods: This cross-sectional study included 122 eyes of 61 women, divided into two groups: 27 healthy pregnant women in the third trimester and 34 age-matched healthy non-pregnant women. Choroidal thickness was measured using Enhanced Depth Imaging OCT at ten different locations: at the fovea and every $500 \mu \mathrm{m}$ from the fovea up to $2500 \mu \mathrm{m}$ temporally and up to $2000 \mu \mathrm{m}$ nasally.

Results: There were no significant differences in the ten measurements of choroidal thickness comparing both groups. Mean subfoveal choroidal thickness was $304.1+9.6 \mu \mathrm{m}$ in the control group and $318.1+15.6 \mu \mathrm{m}$ in the pregnant women group ( $p=0.446$ ). There was also no statistically significant association between gestational age and choroidal thickness measurements in the healthy pregnant women group.

Conclusions: Our study showed no statistically difference in choroidal thickness between healthy non-pregnant women and healthy pregnant women in the third trimester.
\end{abstract}

Keywords: Choroidal thickness, Enhanced depth imaging optical coherence tomography, Pregnancy, Choroid

\section{Background}

Physiological changes during pregnancy are significant and their knowledge is essential to optimize outcomes. Volemia augmentation in pregnancy averages $40-45 \%$ above the nonpregnant blood volume after 32-34 weeks. Cardiac output is increased as early as the 5 th week and reflects a reduced systemic vascular resistance and an increased heart rate [1-3].

Ocular changes during pregnancy like an increased central corneal thickness and curvature and decreased corneal sensitivity and intraocular pressure (IOP) were already described $[4,5]$. Changes in ocular blood flow may also occur, as an increased pulsatile ocular blood flow [6].

\footnotetext{
*Correspondence: camilazbenfica@gmail.com

1 Universidade Federal do Rio Grande do Sul (UFRGS), Porto Alegre, Brazil Full list of author information is available at the end of the article
}

The impact of pregnancy on the choroid, however, is still under investigation, with mixed results. A strong association of central serous chorioretinopathy and pregnancy is well documented $[7,8]$. Choroidal dysfunction and ischemia are also a common ocular complication of preeclampsia [9].

The development of the enhanced depth imaging (EDI) technique of spectral-domain optical coherence tomography (SD-OCT) systems allowed analysis of choroidal morphologic features in normal and pathological eyes [10]. EDI-OCT promotes better documentation of the choroid and choroidal-scleral interface by decreasing signal strength posterior to the retinal pigment epithellium. Since it is a noninvasive diagnostic method, EDI-OCT would be ideal for the study of choroid changes during an uncomplicated pregnancy.

The aim of this study was to compare choroidal thickness measurements of healthy women, pregnant and non-pregnant, using EDI-OCT. 


\section{Methods}

This cross-sectional study included 122 eyes of 61 women, divided into two groups: 27 healthy pregnant women in the third trimester and 34 age-matched healthy non-pregnant women. The participants were recruited between March and September of 2016 at Hospital de Clinicas de Porto Alegre (HCPA), Brazil. All participants received in person full explanation about the study and provided written informed consent. This study was approved by HCPA research ethics committee and was conducted in accordance with the Declaration of Helsinki guidelines.

Participants underwent an interview with demographic and background history and complete ophthalmic examination. Subjects with any previous ocular surgery or ocular pathology including refractive disorders with spherical equivalent greater than \pm 1.0 diopters were excluded. All pregnant women enrolled in the study were attending prenatal care and were having uneventful singleton pregnancy. Participants with history of smoking or diagnosed with any systemic disease, such as diabetes mellitus, hypertension, preeclampsia, renal, rheumatologic or cardiovascular diseases, were also excluded.

All OCT scans were performed in the morning (8:00 am to $12: 00 \mathrm{pm}$ ) to avoid diurnal variations of choroidal thickness $[11,12]$. The same experienced ophthalmologist (CB) performed all OCT scans, using Heidelberg Spectralis OCT (Heidelberg Engineering Co, Heidelberg, Germany). Choroid was imaged with a 6 -line radial scan $\left(30^{\circ}\right.$, $9.2 \mathrm{~mm}$ ) using EDI setting, with 100 images averaged per section. All scans were reviewed before their inclusion in the study; those with image artefacts or inaccurate choroidal limits were excluded. Only one single horizontal scan through the fovea was used for analysis.

Choroidal thickness was determined as the vertical distance from the outer surface of the line formed by the retinal pigment epithelium to the chorioscleral interface using the Spectralis OCT measurement software. The measurements were made by an experienced ophthalmologist (DL) masked to the participant group. Previous studies have already demonstrated the reproducibility of choroidal thickness measurements, even across different OCT systems [13-15]. Choroidal thickness was measured at ten different locations: at the fovea and every $500 \mu \mathrm{m}$ from the fovea up to $2500 \mu \mathrm{m}$ temporally and up to $2000 \mu \mathrm{m}$ nasally (Fig. 1). We used the following abbreviations for the macular points: T5: choroidal thickness at $2500 \mu \mathrm{m}$ temporally to the fovea; T4: choroidal thickness at $2000 \mu \mathrm{m}$ temporally to the fovea; T3: choroidal thickness at $1500 \mu \mathrm{m}$ temporally to the fovea; T2: choroidal thickness at $1000 \mu \mathrm{m}$ temporally to the fovea; T1: choroidal thickness at $500 \mu \mathrm{m}$ temporally to the fovea; SF: choroidal thickness at the fovea; N1: choroidal thickness at $500 \mu \mathrm{m}$ nasally to the fovea; N2: choroidal thickness at $1000 \mu \mathrm{m}$ nasally to the fovea; N3: choroidal thickness at $1500 \mu \mathrm{m}$ nasally to the fovea; N4: choroidal thickness at $2000 \mu \mathrm{m}$ nasally to the fovea.

\section{Statistical analysis}

Statistical analyses were performed using SPSS V.15.0 (SPSS Science, Chicago, Illinois, USA). Quantitative variables from sample demographics were presented as mean \pm SD. To compare variables between groups a t test was used for quantitative data and a Fisher's exact test for qualitative data. Choroidal thickness measures were presented as mean \pm SE. Differences in choroidal thickness were analysed using generalized estimating equations (GEE) with Bonferroni adjustment. Pearson's correlation was used to analyze the relationship between choroidal thickness and gestational age. A p value $\leq 0.05$ was considered statistically significant.

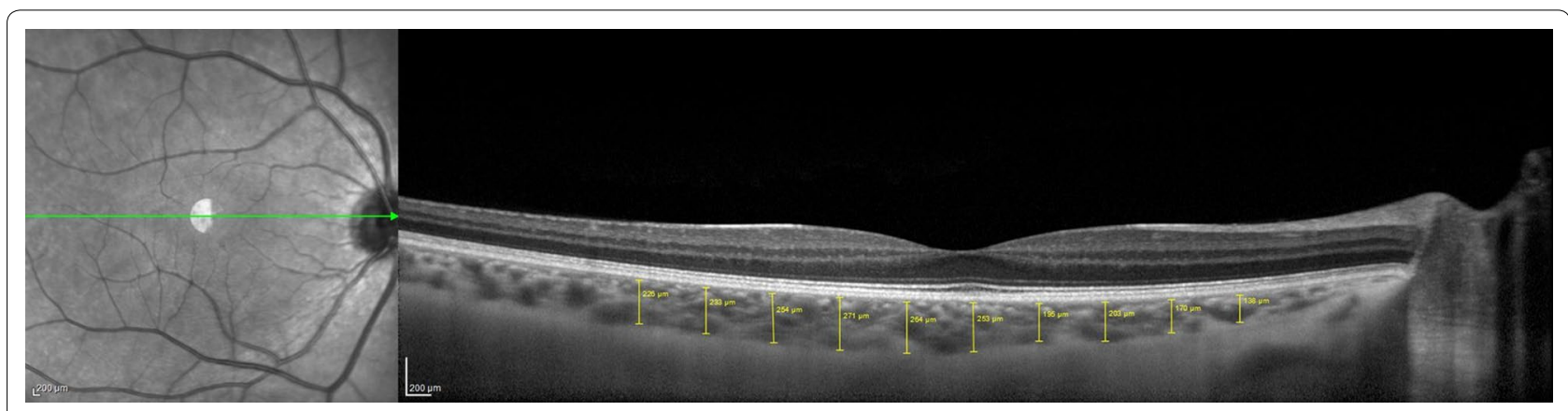

Fig. 1 Measurements of choroidal thickness. Choroidal thickness measured at ten different locations: at the fovea and every $500 \mu \mathrm{m}$ from the fovea up to $2500 \mu \mathrm{m}$ temporally and up to $2000 \mu \mathrm{m}$ nasally 


\section{Results}

This study included 68 eyes of 34 healthy non-pregnant women (Control Group) and 54 eyes of 27 healthy pregnant women in the third trimester (Pregnant Group). Mean age of non-pregnant and pregnant women was $26.8 \pm 5.0$ and $28.1 \pm 7.0$ years, respectively $(\mathrm{p}=0.439$; $\mathrm{t}$ test). Racial distribution included 31 (91.2\%) caucasians and $3(8.8 \%)$ african-american in control group and 25 $(92.6 \%)$ caucasians and $2(7.4 \%)$ african-american in pregnant group ( $\mathrm{p}=1.000$; Fisher's exact test). The mean gestational age in the pregnant group was $33.3 \pm 2.6$ weeks.

The OCT scans were performed in all 54 eyes of the 27 healthy pregnant women and in all 68 eyes of the 34 healthy non-pregnant women. There were no significant differences in the ten measurements of choroidal thickness across the groups. (Table 1) Mean subfoveal choroidal thickness was $304.1+9.6 \mu \mathrm{m}$ in the control group and $318.1+15.6 \mu \mathrm{m}$ in the pregnant group $(\mathrm{p}=0.446)$.

We also analyzed if there was any correlation between the choroidal thickness measurements of both eyes and the gestational week in the third trimester of gestation using Pearson's correlation. There was no statistically significant association between the gestational week and choroidal thickness measurements of both eyes in healthy pregnant women in the third trimester (Table 2).

\section{Discussion}

The choroid is a complex vascular network which provides vascular supply for the retinal pigment epithelium and outer retina layers. It also provides thermal stability for the ocular tissues, removes ocular waste and acts

Table 1 Choroidal thickness measurements of healthy pregnant women in the third trimester and control group

\begin{tabular}{llll}
\hline & $\begin{array}{l}\text { Control group } \\
\text { Mean }+ \text { SE }(\boldsymbol{\mu m})\end{array}$ & $\begin{array}{l}\text { Pregnant group } \\
\text { Mean }+ \text { SE }(\boldsymbol{\mu m})\end{array}$ & p value \\
\hline T5 & $277.4+9.6$ & $278.5+13.9$ & 0.949 \\
T4 & $284.8+10.1$ & $291.5+15.2$ & 0.716 \\
T3 & $292.1+9.8$ & $300.9+14.3$ & 0.611 \\
T2 & $301.7+8.9$ & $308.2+14.8$ & 0.708 \\
T1 & $299.1+8.6$ & $311.2+14.8$ & 0.478 \\
SF & $304.1+9.6$ & $318.1+15.6$ & 0.446 \\
N1 & $285.1+9.6$ & $291.3+14.9$ & 0.730 \\
N2 & $270.3+10.6$ & $267.1+14.7$ & 0.860 \\
N3 & $245.6+10.9$ & $239.4+13.9$ & 0.725 \\
N4 & $213.5+11.5$ & $210.2+12.2$ & 0.843 \\
\hline
\end{tabular}

GEE with Bonferroni adjustment

T5: choroidal thickness at $2500 \mu \mathrm{m}$ temporally to the fovea; T4: choroidal thickness at $2000 \mu \mathrm{m}$ temporally to the fovea; T3: choroidal thickness at $1500 \mu \mathrm{m}$ temporally to the fovea; $\mathrm{T} 2$ : choroidal thickness at $1000 \mu \mathrm{m}$ temporally to the fovea; $\mathrm{T} 1$ : choroidal thickness at $500 \mu \mathrm{m}$ temporally to the fovea; SF: choroidal thickness at the fovea; N1: choroidal thickness at $500 \mu \mathrm{m}$ nasally to the fovea; $\mathrm{N} 2$ : choroidal thickness at $1000 \mu \mathrm{m}$ nasally to the fovea; N3: choroidal thickness at $1500 \mu \mathrm{m}$ nasally to the fovea; N4: choroidal thickness at $2000 \mu \mathrm{m}$ nasally to the fovea in the uveoscleral aqueous drainage and regulation of intraocular pressure $[4,16]$. Choroidal circulation is characterized by a high blood flow controlled by autonomic innervation, while retinal blood flow is mainly determined by autoregulatory mechanisms and local factors [17]. This vascular network is responsible for more than $85 \%$ of the blood flow in the eye and it can be influenced by hemodynamic factors such as blood flow and perfusion pressure [18].

Pregnancy itself promotes metabolic, hormonal and hemodynamic changes which could lead to changes in choroidal blood flow. During pregnancy there is an expansion of blood volume up to $45 \%$, an increase in cardiac output and renin and angiotensin levels, and a decrease in colloid osmotic pressure, vascular resistance and arterial blood pressure [1,3]. There are also some conditions such as central serous chorioretinopathy (CSC) which has an increased prevalence during pregnancy, especially in the third trimester [7, 19]. Previous studies have shown that patients with CSC have thickening of choroid when compared to controls [20, 21]. Choroidal vasodilation and vascular hyperpermeability can cause subsequent vascular leakage and increased hydrostatic pressure in the choroid. The high plasma cortisol concentration may also be a contributor for CSC development in pregnancy. All considered, it is essential to ask whether pregnancy itself can change choroidal structure and thickness.

Traditional imaging modalities such as indocyanine green angiography and Doppler ultrasonography were used in the past to assess choroidal function during pregnancy $[9,22]$. The development of EDI-OCT, however, provided a fast, noninvasive and safe method to analyze choroidal thickness. Choroidal thickness can be influenced by major factors such as age, refractive error and axial length (AL), with increasing age, $\mathrm{AL}$ and decreasing refractive diopter being associated with a reduction of choroidal thickness [23]. Previous authors have measured choroidal thickness during pregnancy, with conflicting results [16, 24-32]. Different methodology may justify these different results. Table 3 summarizes results of different studies comparing choroidal thickness measurements of healthy pregnant and non-pregnant women using EDI-OCT.

Kara et al. [24], Sayin et al. [25] and Atas et al. [26] conducted studies comparing choroidal thickness of healthy pregnant women in different gestational ages with healthy non-pregnant women. The authors concluded that subfoveal choroid was significantly thicker in pregnant women. However, other studies did not find this difference in choroid thickness. Takahashi et al. [27] and Kim et al. [28] demonstrated that choroidal thickness was not significantly different when comparing pregnant 
Table 2 Correlation of gestational week and choroidal thickness measurements of both eyes in third trimester healthy pregnancies

\begin{tabular}{|c|c|c|}
\hline & Pearson correlation coeficiente $(r)$ & $\mathrm{p}$ value \\
\hline \multicolumn{3}{|l|}{ T5 } \\
\hline OD & -0.345 & 0.085 \\
\hline OS & -0.202 & 0.322 \\
\hline \multicolumn{3}{|l|}{ T4 } \\
\hline OD & -0.228 & 0.263 \\
\hline OS & -0.167 & 0.414 \\
\hline \multicolumn{3}{|l|}{ T3 } \\
\hline $\mathrm{OD}$ & -0.234 & 0.250 \\
\hline OS & -0.093 & 0.650 \\
\hline \multicolumn{3}{|l|}{$\mathrm{T} 2$} \\
\hline OD & -0.223 & 0.274 \\
\hline OS & -0.073 & 0.723 \\
\hline \multicolumn{3}{|l|}{$\mathrm{T} 1$} \\
\hline OD & -0.200 & 0.327 \\
\hline OS & -0.141 & 0.492 \\
\hline \multicolumn{3}{|l|}{ SF } \\
\hline $\mathrm{OD}$ & -0.193 & 0.345 \\
\hline OS & -0.213 & 0.295 \\
\hline \multicolumn{3}{|l|}{ N1 } \\
\hline $\mathrm{OD}$ & -0.237 & 0.243 \\
\hline OS & -0.216 & 0.289 \\
\hline \multicolumn{3}{|l|}{ N2 } \\
\hline OD & -0.199 & 0.330 \\
\hline OS & -0.180 & 0.378 \\
\hline \multicolumn{3}{|l|}{ N3 } \\
\hline $\mathrm{OD}$ & -0.144 & 0.482 \\
\hline OS & -0.149 & 0.468 \\
\hline \multicolumn{3}{|l|}{ N4 } \\
\hline $\mathrm{OD}$ & -0.089 & 0.665 \\
\hline OS & -0.143 & 0.487 \\
\hline
\end{tabular}

T5: choroidal thickness at $2500 \mu \mathrm{m}$ temporally to the fovea; T4: choroidal thickness at $2000 \mu \mathrm{m}$ temporally to the fovea; T3: choroidal thickness at $1500 \mu \mathrm{m}$ temporally to the fovea; $\mathrm{T} 2$ : choroidal thickness at $1000 \mu \mathrm{m}$ temporally to the fovea; $\mathrm{T} 1$ : choroidal thickness at $500 \mu \mathrm{m}$ temporally to the fovea; SF: choroidal thickness at the fovea; N1: choroidal thickness at $500 \mu \mathrm{m}$ nasally to the fovea; $\mathrm{N} 2$ : choroidal thickness at $1000 \mu \mathrm{m}$ nasally to the fovea; N3: choroidal thickness at $1500 \mu \mathrm{m}$ nasally to the fovea; N4: choroidal thickness at $2000 \mu \mathrm{m}$ nasally to the fovea

women in their third trimester and healthy non-pregnant women.

Other authors attempted to evaluate choroidal thickness considering gestational age. Goktas et al. [29] conducted a study with 90 healthy pregnant women, 30 at each pregnancy trimester, and 30 non-pregnant healthy women. Choroidal was significantly thicker in second trimester pregnant women in comparison with non-pregnant women. Dadaci et al. [30] compared choroidal thickness measurements of 54 eyes of 27 healthy pregnant women with 50 eyes of 25 nonpregnant women. The pregnant women underwent two OCT scans, one in the first trimester and the other in the third trimester. Choroidal thickness was significantly decreased at all measured points during the third trimester compared to the first trimester. The measurements of the control group were not statistically different.

Ulusoy et al. [16] conducted a prospective study to analyze choroidal thickness in third trimester pregnant women and 3 months after delivery. The subfoveal choroidal thickness was significantly reduced after delivery. A different control group of non-pregnant women was also analyzed and showed significantly thinner choroid measurements in comparison with pregnant women. Rothwell et al. [31] used a different technique to analyze choroid structure by constructing volume macular maps for the 9 subfields defined by the Early Treatment Diabetic Retinopathy Study. The measurements of thickness and volume in the central subfield were significantly greater in third trimester pregnant patients than in nonpregnant patients.

In this study, there were no significant differences in choroidal thickness among the two groups in ten macular points. We also found no significant correlation between choroid thickness and gestational age. These findings did not confirm our initial hypothesis that choroid could be thicker at pregnancy by an overall increase in choroidal blood flow and a decrease in intraocular pressure. However, the results of other studies about choroidal thickness during uncomplicated pregnancy are conflicting, and our findings are similar to those of Takahashi [27] and Kim [28].

Our study has some limitations, such as the small number of subjects. In addition, the cross-sectional design allow us to analyze choroid characteristics only in the third trimester of pregnancy, which could explain our lack of difference, since some authors described thicker choroids specifically at first or second trimesters. More consistent results could be achieved with a longitudinal study of choroidal thickness during the three trimesters of pregnancy and postpartum period with a large number of subjects.

In conclusion, our study reinforces absence of statistical difference in choroidal thickness between healthy third trimester pregnant women and healthy non-pregnant women. Further prospective studies with a larger number of subjects should be performed during different gestational ages and also after delivery. 
Table 3 Summarized results of different studies comparing choroidal thickness measurements of healthy pregnant and non-pregnant women using EDI-OCT

\begin{tabular}{|c|c|c|c|c|}
\hline References & Subjects & Gestational age at exam & $\begin{array}{l}\text { Mean subfoveal choroidal } \\
\text { thickness (SFCT) }\end{array}$ & Conclusion \\
\hline Takahashi et al. [27] & $\begin{array}{l}30 \text { pregnant women } \\
30 \text { non-pregnant women }\end{array}$ & Third trimester & $\begin{array}{l}275 \pm 84 \mu \mathrm{m} \\
273 \pm 92 \mu \mathrm{m}\end{array}$ & $\begin{array}{l}\text { No significant difference in } \\
\text { choroidal thickness between } \\
\text { groups ( } p=0.925)\end{array}$ \\
\hline Sayin et al. [25] & $\begin{array}{l}46 \text { pregnant women } \\
40 \text { non-pregnant women }\end{array}$ & $\begin{array}{l}\text { Variable } \\
28.0 \pm 5.8 \text { weeks } \\
\text { (range: } 17-37 \text { weeks) }\end{array}$ & $\begin{array}{l}368.6 \pm 67.6 \mu \mathrm{m} \\
334.8 \pm 59.9 \mu \mathrm{m}\end{array}$ & $\begin{array}{l}\text { SFCT in normal pregnant women } \\
\text { was significantly thicker than in } \\
\text { non-pregnant healthy women } \\
(p=0.038)\end{array}$ \\
\hline Kara et al. [24] & $\begin{array}{l}100 \text { pregnant women } \\
100 \text { non-pregnant women }\end{array}$ & $\begin{array}{l}\text { Variable } \\
27.3 \pm 6.6 \text { weeks } \\
\text { (range: } 15-38 \text { weeks) }\end{array}$ & $\begin{array}{l}371.1 \pm 61.8 \mu \mathrm{m} \\
337.2 \pm 62.4 \mu \mathrm{m}\end{array}$ & $\begin{array}{l}\text { SFCT in normal pregnant women } \\
\text { was significantly thicker than in } \\
\text { non-pregnant healthy women } \\
(p<0.01)\end{array}$ \\
\hline Atas et al. [26] & $\begin{array}{l}25 \text { pregnant women } \\
26 \text { non-pregnant women }\end{array}$ & Over 28 weeks & $\begin{array}{l}387.2 \pm 60.76 \mu \mathrm{m} \\
322.35 \pm 63.89 \mu \mathrm{m}\end{array}$ & $\begin{array}{l}\text { SFCT in normal pregnant women } \\
\text { was significantly thicker than in } \\
\text { non-pregnant healthy women } \\
(p<0.001)\end{array}$ \\
\hline Goktas et al. [29] & $\begin{array}{l}30 \text { pregnant women in the first } \\
\text { trimester } \\
30 \text { pregnant women in the } \\
\text { second trimester } \\
30 \text { pregnant women in the } \\
\text { third trimester } \\
30 \text { non-pregnant women }\end{array}$ & $\begin{array}{l}\text { First trimester } \\
\text { Second trimester } \\
\text { Third trimester }\end{array}$ & $\begin{array}{l}362 \pm 81 \mu \mathrm{m} \\
395 \pm 80 \mu \mathrm{m} \\
368 \pm 70 \mu \mathrm{m} \\
335 \pm 86 \mu \mathrm{m}\end{array}$ & $\begin{array}{l}\text { SFCT was significantly thicker in } \\
\text { pregnant women in the second } \\
\text { trimester }(p=0.007)\end{array}$ \\
\hline Ulusoy et al. [16] & $\begin{array}{l}29 \text { pregnant women } \\
36 \text { non-pregnant women }\end{array}$ & $\begin{array}{l}\text { Third trimester } \\
3 \text { months after delivery }\end{array}$ & $\begin{array}{l}387.97 \pm 59.91 \mu \mathrm{m} \\
332.40 \pm 26.02 \mu \mathrm{m} \\
320.86 \pm 59.18 \mu \mathrm{m}\end{array}$ & $\begin{array}{l}\text { SFCT significantly increases dur- } \\
\text { ing pregnancy and returns to } \\
\text { normal range } 3 \text { months after } \\
\text { delivery }\end{array}$ \\
\hline Kim et al. [21] & $\begin{array}{l}14 \text { pregnant women } \\
21 \text { non-pregnant women }\end{array}$ & Third trimester & $\begin{array}{l}274.23 \pm 29.30 \mu \mathrm{m} \\
264.95 \pm 21.03 \mu \mathrm{m}\end{array}$ & $\begin{array}{l}\text { No significant difference in } \\
\text { choroidal thickness between } \\
\text { groups }(p=0.325)\end{array}$ \\
\hline Dadaci et al. [30] & $\begin{array}{l}27 \text { pregnant women } \\
25 \text { non-pregnant women }\end{array}$ & $\begin{array}{l}\text { First trimester } \\
\text { Third trimester }\end{array}$ & $\begin{array}{l}\text { OD: } 349.22 \pm 82.11 \mu \mathrm{m} \\
\text { OE: } 341.30 \pm 85.22 \mu \mathrm{m} \\
\text { OD: } 333.56 \pm 76.61 \mu \mathrm{m} \\
\text { OE: } 326.93 \pm 75.84 \mu \mathrm{m} \\
\text { OD: } 318.88 \pm 53.13 \mu \mathrm{m} \\
\text { OE: } 310.60 \pm 51.09 \mu \mathrm{m}\end{array}$ & $\begin{array}{l}\text { Choroidal thickness measure- } \\
\text { ments in the third trimester } \\
\text { were significantly decreased } \\
\text { in both eyes compared to first } \\
\text { trimester measurements }\end{array}$ \\
\hline Rothwell et al. [31] & $\begin{array}{l}12 \text { pregnant women } \\
12 \text { non-pregnant women }\end{array}$ & Third trimester & $\begin{array}{l}319.58 \pm 6.11 \mu \mathrm{m} \\
287.58 \pm 43.44 \mu \mathrm{m}\end{array}$ & $\begin{array}{l}\text { Choroidal thickness in nor- } \\
\text { mal pregnant women was } \\
\text { significantly thicker than in } \\
\text { non-pregnant healthy women } \\
(p=0.034)\end{array}$ \\
\hline Acmaz et al. [32] & $\begin{array}{l}24 \text { pregnant women } \\
38 \text { non-pregnant women }\end{array}$ & After 24 weeks & $\begin{array}{l}393.77 \pm 61.83 \mu \mathrm{m} \\
322.49 \pm 65.58 \mu \mathrm{m}\end{array}$ & $\begin{array}{l}\text { Choroidal thickness in nor- } \\
\text { mal pregnant women was } \\
\text { significantly thicker than in } \\
\text { non-pregnant healthy women } \\
(p<0.001)\end{array}$ \\
\hline
\end{tabular}

\section{Authors' contributions}

CZB participated of the conception, acquisition and analysis of data and drafting of the manuscript. TZ contributed selecting subjects from prenatal care. LBF assisted in the ophthalmological exams. MLRO, LHC and DL analyzed and interpreted the patient data and contributed in writing the manuscript. All authors read and approved the final manuscript.

\section{Author details}

1 Universidade Federal do Rio Grande do Sul (UFRGS), Porto Alegre, Brazil.

${ }^{2}$ Department of Ophthalmology, Hospital de Clínicas de Porto Alegre, Porto Alegre, Brazil. ${ }^{3}$ Department of Gynecology and Obstetrics, Hospital de Clínicas de Porto Alegre, Porto Alegre, Brazil. ${ }^{4}$ Department of Endocrinology, Hospital de Clínicas de Porto Alegre, Porto Alegre, Brazil.

\section{Acknowledgements}

Not applicable.

\section{Availability of data and materials}

The datasets used during the current study are available from the corresponding author on reasonable request.

\section{Competing interests}

The authors report no conflicts of interests.

\section{Consent for publication}

Consent for publication was obtained from the participant whose OCT image was used for Fig. 1. 


\section{Ethics approval and consent to participate}

All participants received in person full explanation about the study and provided written informed consent. This study was approved by Hospital de Clinicas de Porto Alegre research ethics committee (CAAE 33897314.1.0000.5327) and was conducted in accordance with the Declaration of Helsinki guidelines.

\section{Publisher's Note}

Springer Nature remains neutral with regard to jurisdictional claims in published maps and institutional affiliations.

Received: 4 September 2017 Accepted: 9 January 2018

Published online: 29 January 2018

\section{References}

1. Thornburg KL, Jacobson SL, Giraud GD, Morton MJ. Hemodynamic changes in pregnancy. Semin Perinatol. 2000;24(1):11-4.

2. Robson SC, Hunter S, Boys RJ, Dunlop W. Serial study of factors influencing changes in cardiac output during human pregnancy. Am J Physiol. 1989;256:1060-5.

3. Duvekot JJ, Peeters LL. Maternal cardiovascular hemodynamic adaptation to pregnancy. Obstet Gynecol Surv. 1994;49:1-14.

4. Z Zhang J, Wang H, Yu Q, Tong Q, Lu Q. Enhanced depth imaging optical coherence tomography: a new way measuring choroidal thickness in pregnant women. J Ophthalmol. 2017:2017:1-9.

5. Weinreb R, Lu A, Beeson C. Maternal corneal thickness during pregnancy. Am J Ophthalmol. 1988;105(3):258-60

6. Centofanti M, Manni G, Migliardi R, Zarfati D, Lorenzano D, Scipioni M, et al. Influence of pregnancy on ocular blood flow. Acta Ophthalmol Scand. 2002:80(s236):52-3.

7. Haimovici R, Koh S, Gagnon DR, Lehrfeld T, Wellik S. Risk factors for central serous chorioretinopathy: a case-control study. Ophthalmology. 2004;111:244-9.

8. Kuroda S, Ikuno Y, Yasuno Y, Nakai K, Usui S, Sawa M, et al. Choroidal thickness in central serous chorioretinopathy. Retina. 2013;33(2):302-8.

9. Valluri S, Adelberg DA, Curtis RS, Olk RJ. Diagnostic indocyanine green angiography in preeclampsia. Am J Ophthalmol. 1996;122(5):672-7.

10. Spaide RF, Koizumi H, Pozonni MC. Enhanced depth imaging spectral-domain optical coherence tomography. Am J Ophthalmol. 2008;146:496-500.

11. Tan C, Ouyang Y, Ruiz H, Sadda S. Diurnal variation of choroidal thickness in normal, healthy subjects measured by spectral domain optical coherence tomography. Invest Ophthalmol Vis Sci. 2012;53(1):261.

12. Chakraborty R, Read S, Collins M. Diurnal variations in axial length, choroidal thickness, intraocular pressure, and ocular biometrics. Invest Ophthalmol Vis Sci. 2011;52(8):5121.

13. Chhablani J, Barteselli G, Wang H, El-Emam S, Kozak I, Doede A, et al. Repeatability and reproducibility of manual choroidal volume measurements using enhanced depth imaging optical coherence tomography. Invest Ophthalmol Vis Sci. 2012;53(4):2274

14. Branchini L, Regatieri C, Flores-Moreno I, Baumann B, Fujimoto J, Duker J. Reproducibility of choroidal thickness measurements across three spectral domain optical coherence tomography systems. Ophthalmology. 2012;119(1):119-23.

15. Koay C, Quo M, Subrayan V. Reproducibility of choroidal thickness measurements in subjects on 3 spectral domain optical coherence tomography machines. Int Ophthalmol. 2016;37(3):655-71.
16. Ulusoy DM, Duru N, Ataş M, Altınkaynak H, Duru Z, Açmaz G. Measurement of choroidal thickness and macular thickness during and after pregnancy. Int J Ophthalmol. 2015;8(2):321-5.

17. Delaey C, Van De Voorde J. Regulatory mechanisms in the retinal and choroidal circulation. Ophthalmic Res. 2000;32(6):249-56.

18. McDougal D, Gamlin P. Autonomic control of the eye. Compr Physiol. 2015:5(1):439-73.

19. Chatziralli I, Kabanarou S, Parikakis E, Chatzirallis A, Xirou T, Mitropoulos P. Risk factors for central serous chorioretinopathy: multivariate approach in a case-control study. Curr Eye Res. 2017;42(7):1069-73.

20. Imamura Y, Fujiwara T, Margolis R, Spaide R. Enhanced depth imaging optical coherence tomography of the choroid in central serous chorioretinopathy. Retina. 2009;29(10):1469-73.

21. Kim Y, Kang S, Bai K. Choroidal thickness in both eyes of patients with unilaterally active central serous chorioretinopathy. Eye. 2011:25(12):1635-40.

22. Chaine G, Attali P, Gaudric A, Colin M, Quentel G, Coscas G. Ocular fluorophotometric and angiographic findings in toxemia of pregnancy. Arch Ophthalmol. 1986;104(11):1632-5.

23. Xiong S, He X, Deng J, Lv M, Jin J, Sun S, et al. Choroidal thickness in 3001 Chinese children aged 6 to 19 years using swept-source OCT. Sci Rep. 2017;7:450-9.

24. Kara N, Sayin N, Pirhan D, Vural A, Araz-Ersan H, Tekirdag A, et al. Evaluation of subfoveal choroidal thickness in pregnant women using enhanced depth imaging optical coherence tomography. Curr Eye Res. 2014:39(6):642-7.

25. Sayin N, Kara N, Pirhan D, Vural A, Araz Ersan H, Tekirdag A, et al. Subfoveal choroidal thickness in preeclampsia: comparison with normal pregnant and nonpregnant women. Semin Ophthalmol. 2014;29(1):11-7.

26. Ataş M, Açmaz G, Aksoy H, Demircan S, Ataş F, Gülhan A, et al. Evaluation of the macula, retinal nerve fiber layer and choroid in preeclampsia, healthy pregnant and healthy non-pregnant women using spectral-domain optical coherence tomography. Hypertens Pregnancy. 2014;33(3):299-310

27. Takahashi J, Kado M, Mizumoto K, Igarashi S, Kojo T. Choroidal thickness in pregnant women measured by enhanced depth imaging optical coherence tomography. Jpn J Ophthalmol. 2013;57(5):435-9.

28. Kim J, Park M, Kim Y, Kim Y. Comparison of subfoveal choroidal thickness in healthy pregnancy and pre-eclampsia. Eye. 2015;30(3):349-54.

29. Goktas S, Basaran A, Sakarya Y, Ozcimen M, Kucukaydin Z, Sakarya R, et al. Measurement of choroid thickness in pregnant women using enhanced depth imaging optical coherence tomography. Arq Bras Oftalmol. 2014;77(3):148-51.

30. Dadaci Z, Alptekin H, Oncel Acir N, Borazan M. Changes in choroidal thickness during pregnancy detected by enhanced depth imaging optical coherence tomography. Br J Ophthalmol. 2015;99(9):1255-9.

31. Rothwell RT, Meira DM, Oliveira MA, Ribeiro LF, Fonseca SL. Evaluation of choroidal thickness and volume during the third trimester of pregnancy using enhanced depth imaging optical coherence tomography: a pilot study. J Clin Diagn Res. 2015;9(8):NC08-11.

32. Acmaz G, Atas M, Gulhan A, Acmaz B, Atas F, Aksoy H, et al. Assessment of macular peripapillary nerve fiber layer and choroidal thickness changes in pregnant women with gestational diabetes mellitus, healthy pregnant women, and healthy non-pregnant women. Med Sci Monit. 2015:21:1759-64. 